\title{
Argumentatividade e argumentação
}

\author{
Eduardo Guimarães*
}

\section{Resumo}

Este artigo aborda a argumentação do ponto de vista do seu funcionamento no quadro da semântica da enunciação, no âmbito em que ela é definida tendo em vista a caracterização daquele que argumenta. Nesse viés, a argumentação é abordada a partir do conceito de orientação argumentativa, que é a apresentação pelo locutor para seu alocutário de uma relação de sentidos que orienta a direção do dizer, considerada como necessária. Assim concebida, a orientação argumentativa adquire uma natureza linguística. Sustentado na análise de duas sequências do livro Kaspar Hauser ou a Fabricação da realidade, de Izidoro Blikstein, conclui-se que, na argumentação, um lugar social de locutor sustenta uma posição na enunciação e que o sentido da argumentação não é o da persuasão, mas o da sustentação de uma posição, adquirindo, assim, caráter político.

Palavras-chave: Argumentação. Enunciação. Direção argumentativa.
Desde a retomada dos estudos sobre argumentação no final dos anos 1950, vemos surgir diversas abordagens desse aspecto do funcionamento da linguagem. $\mathrm{O}$ meu interesse, neste texto, é discutir um aspecto muito específico desse domínio que se interessa pela argumentação. Por um lado, podemos considerar o estudo da argumentação como o estudo dos modos de persuadir ou convencer alguém (um auditório, como diz a retórica). Essa posição aparece, por exemplo, nos conhecidos trabalhos de Perelman ${ }^{1}$. Por outro lado, a argumentação pode ser tomada como um procedimento de prova, como em Toulmin (1958), ou, ainda, como uma orientação linguística no sentido que Ducrot $(1973,2004)$ dá ao que se chama, na semântica argumentativa, de argumentação na língua. Esses posicionamentos são tomados de pontos de vista muito diversos, e não me interessa aqui discuti-los. Meu objetivo é, simplesmente, apresentar como conce-

DL-IEL/Labeurb - Unicamp. Programa de Pós-Graduação em Linguística. E-mail: eg@reitoria.unicamp.br.

Data de submissão: abr. 2013 - Data de aceite: ago. 2013 http://dx.doi.org/10.5335/rdes.v9i2.3847 
bo a argumentação e como considero seu funcionamento no quadro da semântica da enunciação que venho procurando construir. Ou seja, como definir o que seja a argumentação e como caracterizar aquele que argumenta.

\section{$\mathrm{O}$ acontecimento do funcionamento da língua}

Segundo nossa posição, o acontecimento de enunciação se dá nos espaços de enunciação, o que significa que a língua funciona em relação a outras línguas e seus falantes; ou seja, a relação de enunciação não é uma relação de um locutor com uma língua, mas não é também uma relação falante - ouvinte. Isso porque, no espaço de enunciação, o falante não é, de acordo com minha posição, um ser psico-fisiológico, mas é uma figura determinada por sua relação com as línguas, a qual constitui o falante (GUIMARÃES, 1997, 2000, 2002). Assim, no espaço de enunciação há línguas e falantes. A figura do ouvinte ou outro correlato não tem lugar aí. As relações no espaço de enunciação são do tipo:

\section{Quadro 1: Relações no espaço de enunciação}

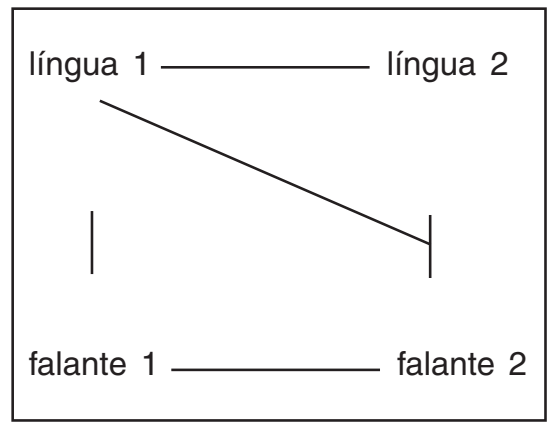

O espaço de enunciação distribui desigualmente as línguas para seus falantes. No esquema hipotético apresentado no Quadro 1, o falante 1 é determinado como falante da língua 1 e o falante 2 , como falante das línguas 1 e 2 , isto é, os falantes, na sua relação com as línguas, afetam-nas e são por elas afetados pelo modo como o sensível é partilhado pelo funcionamento da linguagem (RANCIÈ$\mathrm{RE}, 1995)$. Um outro aspecto importante é que, se os falantes são constituídos nos espaços de enunciação, eles são figuras da enunciação afetadas pelos sistemas de regularidades dessas línguas. Não se fala a partir do nada, mas a partir de uma relação com sistematicidades linguísticas que são as línguas. Um acontecimento enunciativo particular constitui-se pelo funcionamento da língua, na medida em que o falante é agenciado em locutor pelo acontecimento numa cena enunciativa ${ }^{2}$, o que significa, de início, que esse agenciamento movimenta as relações internas das línguas. $\mathrm{Na}$ enunciação, os falantes, agenciados em locutores na cena enunciativa, são agenciados pelas relações internas das línguas e pela relação das línguas, bem como pelo modo como se é tomado como falante numa conjuntura de línguas, em que há uma relação de falantes com as línguas que os constituem, e, portanto, não se trata de uma relação dialógica de um eu e um outro desse eu. Trata-se de uma relação histórica e política com as línguas. As relações entre quem diz e a quem se diz vão constituir o que consi- 
dero a cena enunciativa, constituída pelo agenciamento do falante em locutor no acontecimento da enunciação. Assim, essas relações entre um eu e um tu é uma constituição segunda, estabelecida pela relação histórica da constituição dos falantes.

As relações de argumentação são relações próprias da cena enunciativa. Fazem parte do que agencia o falante em locutor.

\section{Cena enunciativa e argumentatividade}

Para tratar de nossa questão, quem argumenta e o que é a argumentação, consideraremos que a cena enunciativa constitui-se por um conjunto de figuras da enunciação que, de algum modo, "falam" no acontecimento. Para apresentar isso de forma concisa, retomo algumas considerações a propósito de enunciados vocativos que apresentei em outro texto (GUIMARÃES, 2012). Tomemos dois enunciados vocativos bem conhecidos:

(1) Brasileiras e brasileiros

Enunciado que inicia o discurso do então presidente José Sarney, em 18 de maio de 1987, repetindo-se no interior do texto por mais quatro vezes.

(2) Prezado Senhor

Vocativo que vou tomar de uma carta encaminhada à Fapesp por um pesquisador. Reproduzo o início da carta, omitindo nomes: (2a) Ilmo sr.

Prof. Dr. XXXXX YYYY ZZZZZ

Diretor Científico da Fapesp

Prezado Senhor,

De modo sumário, podemos considerar para esses enunciados alguns aspectos relativos à constituição da cena enunciativa.

1. Tanto o "prezado senhor", em (2), quanto "brasileiras e brasileiros", em (1), significam enunciados assumidos por quem os diz, vamos chamar esse lugar enunciativo, que assume o dizer como seu, tal como Ducrot (1984), de locutor (L), e chamaremos seu correlato de alocutário (AL). O L em(1) ou (2) fala ao AL que a própria enunciação constitui em cada caso.

2. Por outro lado, encontramos uma diferença importante, o enunciado vocativo (1) só significa como significa na medida em que esse locutor, que se mostra responsável por ele, não é alguém em abstrato, mas é alguém tomado pelo lugar de presidente da república (no próprio texto ele vai afirmar sua disposição de reduzir seu mandato para 5 anos). Vamos chamar esse lugar enunciativo de locutor-x (ou lugar social de locutor). Esse $\mathrm{x}$ é a variável que a análise deve preencher, no nosso caso o locutor-x é um locutor-presidente. Se observamos o enunciado vocativo (2), veremos que nesse caso o locutor que encaminha algo à Fapesp, ao seu diretor científico, não poderia ser considerado da mesma maneira que no caso do enunciado (1). Para o enunciado (2), vemos que podemos 
dizer que o lugar social de locutor é o lugar de pesquisador. Assim, o locutor-x é um locutor-pesquisador. O correlato do locutor-x é o alocutário-x (al-x), no caso do exemplo um al-institucional.

3. Um outro aspecto a considerar é que, quando o locutor-presidente diz (1), isso se formula, nos textos que integra, com um sentido de universalidade, o locutor diz de um lugar que se significa como universal, e correlatamente é um dizer para todos. Diferentemente disso, no caso de (2), o locutor-pesquisador apresenta-se como um indivíduo específico, que assinou, no final, a carta. $\mathrm{E}$ diz isso para um interlocutor caracterizado por um lugar específico, que poderá lhe dizer sim ou não, segundo certos procedimentos envolvidos no caso. Trata-se de um dizer que se apresenta do lugar individual. A essa diferença de perspectiva do dizer, que constitui o que chamo "lugar de dizer", vamos chamar de enunciador. Nesse caso, teríamos, para o enunciado (1), um enunciador universal, e, para o caso do enunciado (2), um enunciador individual. Nos meus trabalhos ${ }^{3}$, tenho também considerado dois outros enunciadores, ou lugares de dizer, o enunciador genérico, próprio, por exemplo, de provérbios e ditados populares, e o enunciador coletivo, ligado a um lugar, diríamos, corporativo, de um conjunto, que o dizer apresenta como um todo específico. Ao correlato do enunciador, chamamos de destinatário.

Ou seja, consideramos que a cena enunciativa não é unívoca, mas, é constituída pelas seguintes relações:
locutor (L) alocutário (AL)
locutor-x (l-x) alocutário-x (al-x) enunciador (E) destinatário (D)

Assim, ao agenciar o falante em locutor, o acontecimento da enunciação divide, na cena enunciativa, o locutor, sem o que ele não pode ser locutor. Nessa configuração da cena enunciativa é preciso dizer quem aí argumenta, como isso se caracteriza.

Para tratarmos dessa questão, vou tomar duas sequências de um texto (do livro Kaspar Hauser ou a Fabricação da realidade de Izidoro Blikstein) que tenho analisado por outras razões:

(3) (3a) A lição clássica acerca das relações linguagem/percepção/ realidade deveria ser então reformulada: a percepção e a linguagem é que estariam indissoluvelmente ligadas à práxis social, que é indefectível e vital para a existência de qualquer comunidade. Assim é que o exemplo da neve em esquimó também poderia ser revisto e interpretado a partir do esquema proposto no gráfico nํ․ 12 (p. 54).

(3b) Pelo exposto, uma descrição semântica que se pretendesse exaustiva e suficiente deveria abranger os elementos da práxis que modelam a percepção/ cognição e geram a significação do mundo.

(3c) O momento é oportuno para uma indagação fundamental: com que mecanismos a práxis 
engendraria esses elementos "modelantes"? (p. 59-60).

(4) (4a) Por mais inaceitável que seja o referente, (4b) é muito mais cômodo aconchegarmo-nos na confortável ilusão referencial moldada pela práxis comunitária.

(4c) Mas a lição de Kaspar Hauser permanece como um modelo de práxis libertadora.

(4d) Apesar de o mundo ser, na iluminada concepção de G. Bachelard, "primeiro o meu devaneio, depois a minha percepção, em seguida a minha representação, e, enfim, a minha retificação e o meu esquema..." (4e.1), podemos sempre desafiar o esquema $\mathrm{e}$ negar o referente fabricado para a nossa percepção. (4e.2) A exemplo de R. Magritte, podemos dizer que ceci continue de ne pas être une pipe, "isto continua não sendo um cachimbo": (Aqui aparece o quadro de Magritte) (p. Xxx)

Vamos tomar as duas sequências considerando um tipo de articulação linguística reconhecida como argumentativa, tal como faz a semântica argumentativa $^{4}$. Essa articulação argumentativa caracteriza-se por articular uma direção do dizer. Consideremos em (3)

(3a) A lição clássica acerca das relações linguagem/percepção/ realidade deveria ser então refor- mulada: a percepção e a linguagem é que estariam indissoluvelmente ligadas à práxis social, que é indefectível e vital para a existência de qualquer comunidade. Assim é que o exemplo da neve em esquimó também poderia ser revisto e interpretado a partir do esquema proposto no gráfico $\mathrm{n}^{\circ} .12$ (p. 54).

(3b) [Pelo exposto (portanto)], uma descrição semântica que se pretendesse exaustiva e suficiente deveria abranger os elementos da práxis que modelam a percepção/cognição e geram a significação do mundo.

Nesse caso, (3a) articula-se argumentativamente com $(3 \mathrm{~b})$ por uma relação do tipo portanto (A PORTANTO C). Diferentemente disso, consideremos o caso de (4'):

(4') (4d) Apesar de o mundo ser, na iluminada concepção de G. Bachelard, "primeiro o meu devaneio, depois a minha percepção, em seguida a minha representação, e, enfim, a minha retificação e o meu esquema...". (4e) podemos sempre desafiar o esquema e negar o referente fabricado para a nossa percepção. A exemplo de R. Magritte, podemos dizer que ceci continue de ne pas être une pipe, "isto continua não sendo um cachimbo": (p. Xxx) 
Temos em tal fato uma articulação do tipo NO ENTANTO articulando os enunciados que seguem:

(4e.1) podemos sempre desafiar o esquema e negar o referente fabricado para a nossa percepção.

(4e.2) A exemplo de R. Magritte, podemos dizer que ceci continue de ne pas être une pipe, "isto continua não sendo um cachimbo".

(4d) [No entanto/Apesar de] o mundo ser, na iluminada concepção de G. Bachelard, "primeiro o meu devaneio, depois a minha percepção, em seguida a minha representação, e, enfim, a minha retificação e o meu esquema...".

No caso de (3), a enunciação estabelece uma direção do dizer, marcando-o diretivamente (direção conclusiva). Veja como o que segue o enunciado ( $3 b)$ é a formulação de uma pergunta que só pode ser posta pela "conclusão" significada pela sequência ( $3 b)$ introduzida pelo exposto. A pergunta que segue (3b) é

(3c) O momento é oportuno para uma indagação fundamental: com que mecanismos a práxis engendraria esses elementos "modelantes"? (p. 59-60).

Assim, (3a) é argumento e (3b) é conclusão.

O principal, no caso, é que a relação entre (3a) e (3b) instala um sentido tal ao dizer que dele se desdobra, por exemplo, a pergunta (3c), que vem imediatamente depois de (3b). É esse o sentido de orientar (dar uma direção), ao dizer, orientar argumentativamente. Trata-se de uma orientação argumentativa, que vou aqui chamar de argumentatividade linguística.

Referente ao (4'), a articulação argumentativa apresenta uma afirmação em (4e) à qual se opõe (4d). Não porque (4d) seja logicamente oposto a (4e). O que se tem é que a enunciação de (4d) se faz como oposta à enunciação de (4e), como uma articulação concessiva. E o que se observa é que a direção do sentido do texto acompanha o sentido estabelecido por (4e.1), e não por (4d). Observe-se como (4e.2) mantém a direção do dizer estabelecida por (4e.1), e não por (4d). A direção argumentativa é apresentada como inequívoca. Desse modo, consideramos que tanto a relação conclusiva em (3), quanto a relação concessiva em (4') apresentam-se como marcadas pela responsabilidade assumida pelo locutor na relação com seu alocutário. Assim, utilizando \# para representar a concessão (no entanto) $\mathrm{e}-$ ) a conclusão (portanto), podemos apresentar essas relações como segue. Para o caso de (3):

(3') $L$ - (3a) -) $3 \mathrm{~b})-A L$

Para o caso de (4'):

(4") $L-(4 \mathrm{~d}) \#(4 \mathrm{e})-A L$

Nessa medida, podemos definir a orientação argumentativa como a apresentação pelo locutor para seu alocutário de uma relação de sentidos que orienta a direção do dizer apresentando essa direção como necessária. Ou seja, a argumentatividade linguística é significada 
como uma orientação própria da relação do L - AL. Embora por um caminho diverso, trata-se de considerar que a orientação argumentativa não é a busca da persuasão de quem quer que seja, pelo $\mathrm{L}$, o qual não visa convencer, persuadir AL. L - AL e a orientação estabelecida pela relação está no próprio sentido da argumentatividade.

Assim, a argumentatividade linguística nada tem a ver com a consideração da argumentação como a busca da persuasão ou convencimento ${ }^{5}$, sendo simplesmente uma significação que orienta, num certo sentido, o dizer.

Mesmo que tenhamos chegado a uma definição para a argumentatividade linguística, temos que pensar a questão da argumentação relativamente à complexidade da cena enunciativa. Para isso, vou tomar a sequência (4) e analisá-la de modo mais detalhado.

Considerando a sequência (4'), observamos que o que se diz em (4e) pretere o dito em (4d). Veja que nesse caso poderíamos ter

(4d") o mundo é, na iluminada concepção de G. Bachelard, "primeiro o meu devaneio, depois a minha percepção, em seguida a minha representação, e, enfim, a minha retificação e o meu esquema...",

No entanto

(4e.1) podemos sempre desafiar o esquema e negar o referente fabricado para a nossa percepção.
Mas podemos ter também:

(4d") o mundo é, na iluminada concepção de G. Bachelard, "primeiro o meu devaneio, depois a minha percepção, em seguida a minha representação, e, enfim, a minha retificação e o meu esquema...",

portanto

(4e.1) podemos sempre desafiar o esquema e negar o referente fabricado para a nossa percepção.

Trata-se assim, como mostrou Ducrot (2004) a propósito de seus exemplos, que de um mesmo enunciado podemos concluir algo e o seu contrário. Não se trata, portanto, de uma relação veritativa ou demonstrativa.

Mais interessante a observar, ainda, é que nesse caso podemos ter

(4d") o mundo é, na iluminada concepção de G. Bachelard, "primeiro o meu devaneio, depois a minha percepção, em seguida a minha representação, e, enfim, a minha retificação e o meu esquema...",

no entanto

(4e.1') não podemos sempre desafiar o esquema e negar o referente fabricado para a nossa percepção.

O mesmo argumento pode ter uma orientação diretiva ou concessiva relativamente a um mesmo conteúdo se- 
mântico ao qual se articula. Em outras palavras, não se trata de uma passagem de argumento a conclusão. Trata-se de uma relação argumentavia: argumento PORTANTO conclusão ou argumento NO ENTANTO argumento.

Consideremos agora uma outra relação:

(4c) (Mas) a lição de Kaspar Hauser permanece como um modelo de práxis libertadora.

portanto

(4e.1) podemos sempre desafiar o esquema e negar o referente fabricado para a nossa percepção. (4e.2)A exemplo de R. Magritte, podemos dizer que ceci continue de ne pas être une pipe, "isto continua não sendo um cachimbo:

Poderíamos ter, também, a seguinte articulação:

(4c) (Mas) a lição de Kaspar Hauser permanece como um modelo de práxis libertadora.

No entanto

(4e.1') não podemos sempre desafiar o esquema e negar o referente fabricado para a nossa percepção. (4e.2) A exemplo de R. Magritte, podemos dizer que ceci continue de ne pas être une pipe, "isto continua não sendo um cachimbo

Aqui, como no caso da relação $(4 \mathrm{~d})$ - (4e), (4c), pode se dar como um argumento (numa relação diretiva) para $(4 \mathrm{e})$ ou articular-se concessivamente com (4e). Ou seja, o mesmo enunciado pode ter duas relações de argumentatividade opostas. Evidentemente que em cada caso o sentido muda, significando que essa orientação argumentativa do dizer não é um modo de produzir deduções, mas é uma articulação enunciativa de $\mathrm{L}$ que articula os elementos por um dos dois modos de movimentar a argumentatividade. É nesse sentido que consideramos que a orientação argumentativa é uma relação marcada pela relação locutor - alocutário ( $\mathrm{L}-\mathrm{AL}$ ).

Um aspecto importante é que podemos considerar que na medida em que o L toma (14c) como argumento para uma conclusão (4e.1) ou (4e.1'), isso estabelece a direção das relações de sentido. O que está significado em (4c) leva a interpretar o que está em (4e.1) ou (4e.1') como relacionado com o significado (4c), independentemente de qualquer relação veritativa.

Considerando agora a sequência (4), observamos as seguintes relações, atribuídas ao L numa relação com AL (aqui \# significa uma relação de preterição argumentativa (concessão), está colocado ao final do argumento preterido; - ) uma relação diretiva (conclusiva), e r é uma variável que marca simplesmente uma relação de um dizer com um certo domínio de sentido): 
4b.é muito mais cômodo aconchegarmo-nos na confortável ilusão referencial moldada pela práxis comunitária $\longrightarrow$ ) $\sim$ ] \#

4c[(Mas) a lição de Kaspar Hauser permanece como um modelo de práxis libertadora - $\mathrm{r}$ ]l
A.1[[4a. (no entanto/embora) por mais inaceitável que seja o referente -$) \mathrm{r}$ \#

A.2.[[4d.(no entanto/Apesar de) o mundo ser, na iluminada concepção de G. Bachelard, "primeiro o meu devaneio, depois a minha percepção, em seguida a minha representação, e, enfim, a minha retificação e o meu esquema...] \#

4e.1.podemos sempre desafiar o esquema e

negar o referente fabricado para a nossa percepção - $\mathrm{r}$

4.e2 A exemplo de R. Magritte, podemos dizer

que ceci continue de ne pas être une pipe,

"isto continua não sendo um cachimbo"-) r]]

\section{Da argumentatividade à persuasão?}

Esse modo de tratar a questão considera a argumentatividade como uma direção do dizer marcada do lugar de $\mathrm{L}$ e que significa como L mostra como essa articulação argumentativa integra-se ao texto, como se estabelecesse seu modo de organização. É preciso lembrar aqui que o falante é agenciado em L num espaço de enunciação, ou seja, é agenciado em $\mathrm{L}$ inclusive pelas regularidades linguísticas próprias das línguas desse espaço.

Todavia, nem tudo nessa sequência resolve-se pelo reconhecimento das rela- ções acima indicadas. Levando em conta a complexidade da cena enunciativa, de que maneira considerar como se apresenta aí o lugar social de locutor (l-x) e o lugar de dizer, o enunciador $(\mathrm{E})$ ?

Comecemos por observar como cada um dos elementos dessas relações caracteriza-se. Em (4a), encontramos uma forma de dizer em terceira pessoa ("por mais inaceitável que seja o referente"), e de caráter avaliativo, marcado pelo inaceitável, que se opõe ao modo genérico (aconchegarmo-nos) de (4b "é muito mais cômodo aconchegarmo-nos na confortável ilusão referencial moldada pela práxis comunitária"). Podemos, levando isso em conta, considerar, nessa relação, dois enunciadores distintos, vamos 
chamar o primeiro de E1 e o segundo de E2. Depois, temos que considerar que essa diferença também se apresenta se comparamos

(4c) [(Mas) a lição de Kaspar Hauser permanece como um modelo de práxis libertadora

$\mathrm{e}$

(4e) (4e.1) podemos sempre desafiar o esquema e negar o referente fabricado para a nossa percepção -) $\mathrm{r}$

4.e2 A exemplo de R. Magritte, podemos dizer que ceci continue de ne pas être une pipe, "isto continua não sendo um cachimbo" 一) $r$.

No primeiro caso, temos a forma de terceira pessoa, num modo narrativo e, no segundo, a marcação de pessoalidade. Essa marcação aqui se configura de modo mais forte pela presença da expressão podemos desafiar. É curioso observar que (4d) (no entanto/Apesar de) o mundo ser, na iluminada concepção de G. Bachelard, "primeiro o meu devaneio, depois a minha percepção, em seguida a minha representação, e, enfim, a minha retificação e o meu esquema...", que poderia ser considerada como uma formulação em terceira pessoa, até porque é uma forma de discurso relatado, tem uma característica que a faz significar de um modo um pouco distinto. Ao apresentar o dizer de Bachelard (em 4d), o enunciado traz claramente, um modo de marcar individualmente o dizer. Podemos então considerar que temos aí para (4c) um enunciador -3 (E3); em (4d), um enunciador-4 (E4); e em (4e), um enunciador-5 (E5). Dizemos, assim, que E1 é um enunciador individual, que E2 é um enunciador genérico, no qual o locutor está incluído, que E3 é um enunciador universal, afirmando o centro da "verdade" da argumentação, que E4 e E5 são um enunciador individual. Desse modo, teríamos o seguinte:

\section{Quadro 3}

[E1 (ind) - (4a) (no entanto/embora) por mais inaceitável que seja o referente - ) r \#

E-2 (gco)- (4b) é muito mais cômodo aconchegarmo-nos na confortável ilusão referencial moldada pela práxis comunitária $\longrightarrow$ - $\sim$ r] \#

E3 (univ.) - 4c[(Mas) a lição de Kaspar Hauser permanece como um modelo de práxis libertadora - r $]-$ ] [ E-5 (ind.) - 4e.1. podemos sempre desafiar o esquema e negar o referente fabricado para a nossa percepção e A exemplo de R. Magritte, podemos dizer que ceci continue de ne pas être une pipe, "isto continua não sendo um cachimbo" -) $r$

E4 (ind.) - [4d. (no entanto/Apesar de) o mundo ser, na iluminada concepção de G. Bachelard, "primeiro o meu devaneio, depois a minha percepção, em seguida a minha representação, e, enfim, a minha retificação e o meu esquema...",] \# 
No entanto, temos que observar, ainda, que, dada a configuração que apresentamos para o que é a orientação argumentativa, temos: L assume E3 e E5, em que, a argumentavidade (do locutor) apresenta-se por uma homogeneização de uma polifonia, de uma divisão do dizer. Então, estamos diante de uma questão interessante, a diretividade do texto é uma construção do locutor, mas a sequência do texto não significa simplesmente nessa direção, tanto que outras vozes falam. Por exemplo, o próprio argumento dominante pela articulação argumentativa apresenta-se de uma voz universal da ciência (E3), mas disso se desdobra, como sentido, um dizer de uma voz individual (E5), como conclusão. E assim podemos encontrar uma conexão entre o dito em (4a), (no entanto/embora) por mais inaceitável que seja o referente -) r; e em (4e), podemos sempre desafiar o esquema e negar o referente fabricado para a nossa percepção e, a exemplo de R. Magritte, podemos dizer que ceci continue de ne pas être une pipe, "isto continua não sendo um cachimbo" -) r.

O outro aspecto que precisa ser levado em conta é o do lugar social do locutor. Observando a passagem central da argumentação, destacado acima em negrito, vemos que, de um lugar universal, o L apresenta uma continuidade do dizer do lugar individual. Assim, nesse caso, mais que encontrarmos aí a presença da orientação argumentativa do L, podemos reconhecer que esse ponto da sequência mostra-nos uma indicação importante para considerarmos o lugar social do locutor. Trata-se de um lugar que se marca, também, pela afirmação de "podemos sempre desafiar", numa forma claramente "militante" para a apresentação do desdobramento da conclusão do texto. Vamos, então, considerar que essa sequência apresenta como l-x um l-"militante" (por falta de outro nome, mesmo sabendo das dificuldades dessa nomeação), tendo assim:

Quadro C

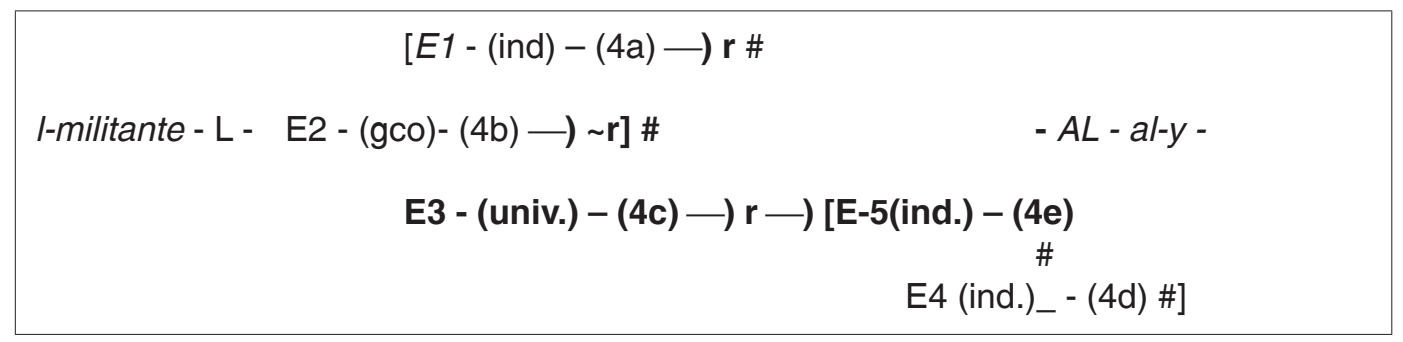

Dada essa descrição das relações da cena enunciativa, somos levados a considerar que o $\mathrm{L}$ estabelece a relação de orientação argumentativa cujo centro é, nessa sequência, o que está em negrito
(E3 - (univ.) - (4c) -) r ) E-5(ind.) (4e)). E, como dissemos, há outras vozes e outras relações de vozes na divisão do locutor na cena enunciativa, sendo uma delas a voz do l-“militante”. Lugar social 
do locutor que não assume necessariamente a mesma relação estabelecida pela orientação argumentativa de L. Assim, podemos observar outras marcas que essa sequência tem: o inaceitável em (4a), o iluminada em (4d) e o podemos desafiar em (4e.1). Isso significa um outro movimento que também poderíamos considerar como argumentativo. Só que agora, se trataria de ver como o l-x busca argumentar para o al-x constituído pelo texto.

A sequência (4) que estamos analisando termina com uma conclusão, da orientação argumentativa de L, que é dita por um l-“militante”. Esse locutor-militante, ao dizer "podemos desafiar o esquema", sustenta o desafio ao esquema, ao estabelecido. Desse modo, o l-“militante" configura um al-x para o qual o sentido do desafio, da "liberdade" é argumento decisivo. Poderíamos inicialmente considerar esse aspecto, como a busca de uma persuasão, de um convencimento, como um aspecto retórico da argumentação. E nesse caso atribuiríamos esse aspecto à relação l-x - al-x, mas o al-x não é um correlato direto específico e necessário de um l-x, tal como vimos na caracterização do funcionamento de enunciados vocativos.

Ao ser agenciado em locutor, o falante é agenciado em locutor-x. Na relação L - AL há uma correlação direta. No caso de l-x, tem-se algo diverso, pois:

$$
\begin{array}{ll}
-a l-x 1 \text { ou } \\
\text { l-x } & -a l-x 2 \text { ou } \\
- \text {-al-x3 ou } \\
-. . .
\end{array}
$$

Isso significa que o l-x não tem um correlato direto específico como no caso de $\mathrm{L}$ - AL, pois o falante é que é agenciado em locutor. O l-x, enquanto lugar social do dizer, tem como correlato um al que o dizer configura. No entanto, se o lx- constitui um al-x, é preciso considerar que al está no lugar da interpretação, afetado, então, por uma outra temporalidade. Isso projeta que a interpretação pelo outro do dizer de l-x pode ser de um outro lugar que não o de al-x. Em outras palavras, a interpretação é de um certo al-y que pode sempre ser outro. Há, assim, um embate configurado pela disparidade própria da enunciação ${ }^{6}$.

\section{Conclusão}

Se a argumentatividade não significa a construção da persuasão, a argumentação do lugar social de locutor (al-x) também não. Desse modo, a persuasão não é constitutiva nem de uma nem de outra. Assim, se a persuasão não é própria da orientação argumentativa estabelecida na relação $\mathrm{L}$ - AL, que é uma relação de sentido, também não é própria do que estamos chamando de argumentação, pois o lugar de al-x não é o correlato direto do l-x, e, mais que isso, o lugar de leitor, tal como dissemos em Guimarães (2012), ou seja, o lugar de interpretação do dizer, se dá num acontecimento diverso do acontecimento do dizer. $\mathrm{O}$ acontecimento da interpretação tem outra temporalidade, é de outro tempo, o que nos leva a considerar que a argumentação não diz 
respeito à persuasão, definindo-a como o processo pelo qual um lugar social de locutor sustenta uma posição na enunciação. O sentido da argumentação não é o da persuasão é o da sustentação de uma posição, e, nesse sentido, é política.

\section{Argumentativity and Argumentation}

\section{Abstract}

This article approaches the argumentation of the point of view of its operation in the framework of enunciation semantics, within the scope of which it is defined taking into account the characterization of those who argue. From this outlook, argumentation is seen based on the idea of argumentative orientation, which is the presentation by Locutors to their Allocutors, of a relation of meanings that shape the direction of what is said, considered as necessary. Seen like this, argumentative orientation acquires a linguistic nature. Sustained in the analysis of two sequences of the book Kaspar Hauser or a Fabricação da Realidade, by Izidoro Blikstein, it follows that in argumentation a social place of speaker sustains a position in the enunciation, and that the meaning of the argumentation is not persuasion, but the sustainability of a position, acquiring, like this, a political character.

Keywords: Argumentation. Enunciation. Argumentative direction.

\section{Notas}

1 Ver particularmente Perelman e Olbrechts-Tyteca (1958).

2 No sentido que dou a esse termo. Ver, por exemplo, Guimarães (2002).

3 Ver Guimarães (2002), por exemplo.

4 Ver, por exemplo, Ducrot $(1983,1990,2004)$ e Anscombre e Ducrot (1987).

5 Sigo, em certa medida, o que diz Ducrot (2004). A diferença é que para mim esta argumentatividade é constituída pela relação $\mathrm{L}-\mathrm{AL}$ na cena enunciativa, e para ele trata-se de algo relativo à significação própria da língua.

6 Sobre isso, ver Guimarães (2012).

\section{Referências}

ANSCOMBRE, J.-C.; DUCROT, O. l'Argumentation dans la langue. Bruxelas: Mardaga, 1987.

DUCROT, O. (1973). As escalas argumentativas. Provar e dizer. São Paulo: Global, 1983. . (1984). O dizer e o dito. Campinas: Pontes, 1987.

Editora, 1990.

Polifonia y argumentacion. Cali:

Argumentation rhétorique et argumentation linguistique. In: DOURY, M.; MOIRAND, S. (Orgs.). L'Argumentation aujourd'hui. Positions théoriques en confrontation. Paris: Sorbonne Nouvelle, 2004. GUIMARÃES, E. Política de línguas na América Latina. In: Encontro sobre politica linguística na América Latina, UBA, Buenos Aires, 1997.

. O Político e os espaços de enunciação. Conferência no "I Encontro Nacional Linguagem, História, Cultura. Cáceres: Unemat, 2000.

. Semântica do acontecimento. Campinas: Pontes, 2002.

. Ler um texto. Uma perspectiva enunciativa. Conferência, Abralin em Cena, Cuiabá, 2012.

PERELMAN, Ch.; OLBRECHTS-TYTECA, L. (1958) Traité de l'argumentation. La nouvelle rhétorique. Cidade: Editions de l'Unviersité de Bruxelles, 1970.

RANCIÈRE, J. La Mésentente. Paris: Galilée, 1995. 